THE USE OF THE SIGMOIDOSCOPE AS AN AID TO DIAGNOSIS IN

\title{
CHRONIC DYSENTERY.
}

\author{
BY
}

PHILID MANSON-BAHR, D.S.O., M.D., M.R.C.P., Physician to the Hospitalfor Tropical Diseases. AND

A. L. GREGG, M.A., M.D., B.CH., B.A.O., Medical Superintendent, Hospital for Tropical Diseases.

The correct diagnosis of relapsing dysentery, or of chronic diarrhoea, amongst war pensioners, is a matter of very considerable importance from an individual, as well as from a national point of view. Considerable difficulty may be experienced in making a diagnosis by a simple microscopical examination of the faces in men who contracted their dysentery three or four years ago, and it will be our object to point out how this difficulty may, to a great extent, be overcome.

The chronicity of these cases, as well as their tropical origin, would at first sight suggest that the majority are amobic, and this statement, to a great extent, proves to be correct ; but it by no means follows that all are due to the Entamaba histolytica. Quite a number are not, and these non-amoebic diarrhceas are by no means improved-it may be that their symptoms are aggravated-by a misdirected anti-amobic treatment.

Sometimes little assistance may be gained from a consideration of the patient's history alone, for it is not exceptional to encounter cases in whom the primary diagnosis during active service was bacillary dysentery, but who in their subsequent military career contracted amobiasis. Mere physical examination of the patient can provide little definite assistance.

It. is true that, as a rule, chronic bacillary cases, whose mucosa has been to a considerable extent destroyed, are more emaciated and bed-ridden than are the chronic amobic ones,

Palpation of the abdomen in the former disease may fail to reveal any localised tender spots, whereas amebic cases more usually exhibit areas of deep tenderness situated over the course of the large intestine, especially the cæcum and transverse colon.

We wish to emphasise that in the bacillary disease it is the terminal portion of the large gut which is most seriously affected, a circumstance which renders sigmoldoscopic examination so valuable in this condition, especially as a positive diagnosis cannot be obtained by any other method. We wish to explain briefly why this is so.

The pathological changes present are due to fibrosis and the deposition of granulomatous tissue- the aftermath of the acute bacillary disease. Therefore a simple microscopic examination of the fæces is of a purely negative value, nor can we expect to obtain much assistance from cultures for the dysentery bacilli, as these have long disappeared. Serological reactions also have long ceased to be of any diagnostic importance in these cases.

It is well known that in amoebiasis an amœbic carrier may pass numerous cysts of E. histolytica on one or two occasions, but that subsequent exammations-it may be for days, or even weeks on end-may fail to reveal any traces of this organism. We may instance one particular case, in which eleven fral specimens were examined, with a 
negative result, but on the twelfth occasion numerous characteristic cysts were seen; this occurred in a patient who was being actively purged, and was passing stools containing mucus and blood at the time.

One is justified in assuming that cases of this nature are by no means exceptional.

There are also cases - three of which have recently been encountered-in which active entamœbæe were found in the blood-stained mucus passed during a brief exacerbation, but who subsequently continued to void faces containing neither the vegetative forms nor their cysts. Microscopic examination of the freces for the E. histolytica, or its cysts, is a very necessary procedure, and we do not wish to make any statements which would bring such a well-established method into disrepute, but it has its limitations, as every experienced microscopist will admit.

It is now clear that, as a routine method of excluding an amobic infection, many microscopical stool examinations are required for each patient, and, incidentally, many days must elapse before a definite diagnosis can be made or a rational treatment instituted. Any system, then, which tends to obviate this delay is to be encouraged as saving both time and money.

During the past year, we have employed the sigmoidoscope as a means of assisting diagnosis and in controlling treatment, and by this means, when used as a routine in chronic dysentery, we think that we can overcome the difficulties we have detailed and shorten the patient's stay in hospital, and thereby save the State considerable expense.

The advantages of the routine use of the sigmoidoscope are :-

(1) A rapid and accurate diagnosis by direct vision can often be made.

(2) Unsuspected intestinal conditions, such as hæmorrboids, syphilitic stricture, malignant disease or polypi are occasionally revealed.

(3) The proportion of cases of doubtful etiology is considerably reduced.

The method adopted in making a sigmoidoscopic examination is comparatively simple, but it is necessary to emphasise one or two points.

The preparation of the patient for rectal examination requires consideration. $\mathrm{He}$ should be purged so that the large bowel is emptied of faces, but at the same time it must not be rendered too irritable.

We have found that the most satisfactory method consists in administering half an ounce of castor oil on the previous evening; followed in the morning by a soap and water enema so as to completely clear out the rectum.

In order to render the bowel less sensitive to manipulation, and to check peristalsis, we find it advisable to administer $15 \mathrm{~min}$. of Tinct. opiz immediately after the enema.

In cases where there is incessant diarrhcea a satisfactory method of clearing out the bowel has yet to be discovered, but, fortunately, in these cases a fleeting glimpse of a small portion of the bowel usually suffices to establish a diagnosis.

As regards the posture assumed by the patient during examination, we prefer the lithotomy position. This position causes any fluid contents of the bowel to collect in the dorsal aspect of the rectum, which acts as a sort of a trap, while the bowel, both above and below this pool, may be minutely scrutinised.

It is quite unnecessary, indeed to our minds it is inadvisable, to administer an anæsthetic. 'We should be guided by the patient's sensations of pain and discomfort while the instrument is being passed.

Naturally, when one intends to examine an ulcerated bowel, great care should be taken in introducing the instrument, and when once the sphincter muscles have been passed its further passage should be guided by sight alone.

The degree of pain experienced varies greatly. Generally it is much greater in the bacillary types than in the amcbic disease; it is much greater in highly-strung and nervous individuals than in less sensitive snbjects. The ulceration of the bowel itself would seem to have little bearing upon this point, for some cases with extensive uiceration complain of little discomfort whilst being examined.

It is wise not to disregard any sudden pain of which the patient complains, for this is generally due to too great pressure being exercised upon one particular portion of the bowel wall. 
The distance to which the instrument can be passed also varies considerably; in some a length of only four inches, in others, again, twelve inches or so, may be reached with ease, till the point of the sigmoidoscope can be distinctly felt in the left hypochondrium.

\section{Appearances of Amcebic Ulceration.}

The following lesions can be made out:-Discrete diamond-shaped ulcers of varying size and extent with hæmorrhagic margins and greenish or grey basal sloughs. Some appear to be quite shallow, others of some considerable depth. The intervening mucous membrane is healthy in appearance and yellowish-pink in colour, though generally it is more redundant than is the normal. On the whole, the lesions resemble those seen at autopsy, but it has struck us that the small petechial hamorrhages which are obscured after death and the general vivid colouration of the blood clots which cover the smaller ulcers are much more striking than when seen in the dead body.

This is what one would expect from a study of living tissues.

In a small percentage of undoubted, that is, microscopically diagnosed amobic cases, the rectum is not ulcerated at all; in these instances it is probable that the amcebic lesions are situated in the upper part of the large bowel beyond the range of vision through the sigmoidoscope, and the stools in these cases usually contain $E$. Kistolytica cysts, rather than vegetative entamœbæ.

Important as are the sigmoidoscopic appearances, much information may be obtained from microscopical examinations of the scrapings of these ulcers.

The best instrument for this purpose is a wooden match affixed to a holder and introduced through the sigmoidoscope. By this means individual ulcers may be scraped and the exudate derived from them microscopically examined. It is possible by this method to demonstrate active entamoebæ in considerable numbers together with CharcotLeyden crystals, which themselves are possibly diagnostic of amcebiasis (J. GoRDon ThOMSON) in cases in which several fæces-examinations have proved to be negative.

\section{Sigmoldoscopic Appearances in the Bacillaky Cases.}

The lesions seen in the lower bowel in this very serious condition consist for the most part of granulation tissue, and represent an attempt on the part of the bowel to replace, as far as possible, the tissues originally destroyed by the primary specific necrosis. Inflammatory changes, when present, are due probably to a secondary invasion of the badly-lacerated mucosa by intestinal organisms other than the dysentery bacillus.

We have not seen cases where ulceration of the bacillary type was actually present in the rectum. The changes we have seen can be classified, according to their severity, as follows :-...

(I) The mildest form appears as a slight hyperæmia of the mucosa, which is more sensitive than usual to the passage of the instrument.

(2) Acute hyperremia of the mucosa, together with a sightly granular and glazed appearance throughout the rectal canal, or, it may be, occupying definite zones, three or four inches in diameter.

(3) Masses of granulation tissue superimposed upon an atrophic and fibrotic mucous membrane.

(4) Granulomatous polypi arising from a hyperæmic or hæmorrhagic bowel wall. This condition may extend throughout the large intestine, for similar changes have been found in the crecum of two cases at operation.

Cases with lesions of this extreme severity are usually in a critical condition.

We append statistics to illustrate the points alluded to in this paper, and we wish to thank Dr. G. C. Low for so kindly permitting us to utilise figures obtained from cases under his care, as well as permitting us to exhibit drawings made from one of his patients. 
Diagnoses in One Hundred Consecutive Cases of Suspectet Dysentery.

\begin{tabular}{|c|c|c|c|}
\hline \multicolumn{4}{|c|}{ By Sigmoidoscope. } \\
\hline Positive amobic & $\ldots$ & $\ldots$ & $29 !$ \\
\hline Suggestive , & $\ldots$ & $\ldots$ & $13 \sqrt{42}^{2}$ \\
\hline Positive bacillary & $\ldots$ & $\cdots$ & 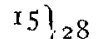 \\
\hline Suggestive ", & $\cdots$ & $\ldots$ & $13 f^{20}$ \\
\hline \multicolumn{4}{|c|}{ Other causes of symptoms:-- } \\
\hline Rectal polypus & $\ldots$ & $\ldots$ & $\mathbf{r}$ \\
\hline Hæmorrhoids & $\ldots$ & $\ldots$ & 4 \\
\hline Syphilitic stricture & $\ldots$ & $\ldots$ & $\mathrm{r}$ \\
\hline Etiology undiagnosed & $\ldots$ & $\ldots$ & I I \\
\hline Normal appearance & $\cdots$ & $\ldots$ & $\tau_{4}$ \\
\hline & & & $10 \mathrm{I}$ \\
\hline
\end{tabular}

By Microscope.

Positive amobic (Charcot-Leyden

$\begin{array}{cccc}\text { erystals, etc.) } & \ldots & \ldots & 30 \\ \text { Suggestive amcebic } & \ldots & \ldots & \text { I }\end{array} 3^{\text {I }}$

Positive bacillary $\quad \ldots \quad \ldots \quad$ of 5

Suggestive ", $\quad \ldots .4$ f $^{5}$

Remaining of little positive

value $\quad \ldots \quad \ldots \quad \ldots 2$ I 1 exams.

Total microscopical exams. done on these roo cases ... 247

Only two cultures were made-both negative.

These preliminary examinations were all performed before a diagnosis was established.

\section{Details of Signoidoscope Results.}

44 positive diagnoses were made, and of these-

2o were confirmed by the microscope.

I 5 others were confirmed by the clinical history of the patient.

In 8 the clinical history was doubtful, and confirmation of the diagnosis is lacking.

In $\mathrm{I}$ the history disagreed with the diagnosis, which was proved clinically to be correct.

26 suggested diagnoses were given, and of these-

6 were confirmed by the microscope.

10 others were confirmed by the clinical history.

In 5 the clinical history was doubtful, and confirmation of the diagnosis is lackmn.

In 5 our diagnosis was probably wrong.

Thus there were $5^{2}$ confirmed diagnoses of amœebic or bacillary dysentery, and there were 6 cases in which the symptoms were caused by other local conditions, such as hæmorrhoids, etc.

Of the remaining 43 findings-

II were undiagnosed.

14 appeared normal, and of these-

6 had no symptoms, and were discharged.

I had E. histolytica cysts and a liver abscess, but had never had dysentery.

2 had $E$. histolytica cysts in their stools.

3 gave a history of amœbic dysentery.

I gave a history of bacillary dysentery.

In $t$ the clinical history was doubtful.

13 lack confirmation.

In 5 our diagnosis was probably wrong.

In other words, the sigmoidoscope was instrumental in giving a positive diagnosis, that is, a confirmed diagnosis, in 58 per cent., while in the same hundred cases the microscope alone gave 31 per cent. 


\section{RICKETTSIA IN THE BED-BUG: DEMONSTRATION.}

Mr. A. BACOT gave a demonstration showing a species of Rickettsia in the bed-bug which, although it has probably been noticed before, in one or other of its stages, has not apparently received serious attention or comment. Rickettsia bodies are a new group. It is now generally admitted that they are organisms showing many resemblances to bacteria in their staining reaction and morphology, but, in the absence of definite cultural successes, it is impossible to say how nearly related to bacteria they may be. They are usually diplococcoid in form, and have staining capacities in common. Rickettsia bodies are associated with Rocky Mountain spotted fever, conveyed by ticks, trench fever, and typhus fever conveyed by the body louse, and, I think, Japanese river fever conveyed by mites. Some persons consider them to be the causal organisms of these diseases; others think they are not associated with the disease itself but only with the insect conveying the disease. The species which my colleagues, Dr. ATKIN and Dr. Arkwright, and myself found in the bed-bug exbibits considerable similarities in its development to Rickettsia prowazeki, the supposed causal organism of typhus fever. It is intracellular, and in addition to the diplococcoid form shows both bacterial and thread-like phases. These latter forms are not seen in the Rickettsia associated with trench fever. In other respects, however, the species in the bed-bug is more akin to that which NöLLER described as occurring in the "sheep ked' (Melophagus ovinus). It passes from generation to generation through the egg, and, so far as is known, has no second host. The eggs become infected before they are lard. In the intracellular stage clusters occur in the cytoplasm of the cell. A smear of the ovary shows both minute pointed-ended forms together with developing bacillary forms. Examples of the long bacillary forms are also shown under one of the microscopes. In certain cells of the Malpighian tubules the development is very pronounced, the cell becoming greatly enlarged; it may be two or even three times the diameter of the normal tube. If these enlarged cells are broken or cut across, the interior is found to be filled with a mass of long thread forms, and sometimes a considerable proportion of the minute coccoid bodies are present as well.

Apparently all bed-bugs are infected, and this is thought to be also the case with the "sheep ked."

I would like to ask any members who come across the species of Cimex which infest the haunts of pigeons or bats, kindly to communicate with Dr. ATKIN or myself, as we are anxious to ascertain if the bugs of animals other than man are infected. 